\title{
Many roads lead to Rome: Self-regulatory strategies and their effects on self-control
}

\author{
Hennecke, Marie ; Bürgler, Sebastian
}

\begin{abstract}
In a self-control conflict, people face a dilemma between a current goal (e.g., to exercise regularly) and competing impulses, habits, or desires (e.g., to stay on the couch and continue watching TV). To resolve such conflicts in favor of their goals, individuals may capitalize on a variety of selfregulatory strategies. In this article, we review recent research on the self-regulatory strategies people use in their daily lives, research on the effectiveness of these strategies, and research on the consequences of self-regulatory strategy use on well-being. We furthermore take both an individual-differences and a situational perspective by linking strategy use to individual differences between people (e.g., in selfcontrol) and by emphasizing that strategy effectiveness likely depends on situational context (e.g., on current demands). Finally, we introduce ideas and potential future research questions revolving around the role of individual differences in regulatory flexibility (including context-sensitivity) for determining a person's self-regulatory success
\end{abstract}

DOI: https://doi.org/10.1111/spc3.12530

Posted at the Zurich Open Repository and Archive, University of Zurich

ZORA URL: https://doi.org/10.5167/uzh-209981

Journal Article

Published Version

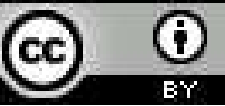

The following work is licensed under a Creative Commons: Attribution 4.0 International (CC BY 4.0) License.

Originally published at:

Hennecke, Marie; Bürgler, Sebastian (2020). Many roads lead to Rome: Self-regulatory strategies and their effects on self-control. Social and Personality Psychology Compass, 14(6):1-16.

DOI: https://doi.org/10.1111/spc3.12530 


\section{Many roads lead to Rome: Self-regulatory strategies and their effects on self-control}

\section{Marie Hennecke ${ }^{-1}$ | Sebastian Bürgler}

University of Siegen, Siegen, Germany

\section{Correspondence}

Marie Hennecke, University of Siegen,

Department of Psychology,

Adolf-Reichwein-Str. 2a, 57068 Siegen,

Germany.

Email: marie.hennecke@uni-siegen.de

\section{Funding information}

Swiss National Science Foundation, Grant/

Award Number: 100019_179207

\begin{abstract}
In a self-control conflict, people face a dilemma between a current goal (e.g., to exercise regularly) and competing impulses, habits, or desires (e.g., to stay on the couch and continue watching TV). To resolve such conflicts in favor of their goals, individuals may capitalize on a variety of self-regulatory strategies. In this article, we review recent research on the self-regulatory strategies people use in their daily lives, research on the effectiveness of these strategies, and research on the consequences of self-regulatory strategy use on wellbeing. We furthermore take both an individual-differences and a situational perspective by linking strategy use to individual differences between people (e.g., in self-control) and by emphasizing that strategy effectiveness likely depends on situational context (e.g., on current demands). Finally, we introduce ideas and potential future research questions revolving around the role of individual differences in regulatory flexibility (including context-sensitivity) for determining a person's self-regulatory success.
\end{abstract}

Good self-control is a highly desirable trait. Being able to act in the interest of one's goals even in the face of competing impulses, habits, and desires, appears to be necessary for living a successful, healthy, and happy life: In fact, self-control supports high achievement at school and work, helps people to control their body weight, makes them stay away from drugs and crime, promotes the experience of satisfying personal relationships, and generally fosters well-being and psychological adjustment (De Ridder, Lensvelt-Mulders, Finkenauer, Stok, \& Baumeister, 2012; Hofmann, Luhmann, Fisher, Vohs, \& Baumeister, 2014; Moffitt et al., 2011; Tangney, Baumeister, \& Boone, 2004). It may seem like there is nothing that good self-control cannot do. 
Unfortunately, not everyone excels at self-control and people differ with regard to how good they are at controlling themselves. The trait that describes these individual differences can be defined as the "ability to override impulses to act as well as the ability to make oneself initiate or persist in boring, difficult, or disliked activity" (Carver, 2019, p. 477). Relatively little, however, is known about the specific processes that underlie this ability, the processes by which the trait "gets outside the skin" (Hampson, 2012, p. 315), or in other words, what it is exactly that people with higher levels of self-control do, experience, think, or feel differently than people with lower levels of self-control. Knowing about these processes, however, would be a key to designing effective interventions aimed at improving people's self-control.

For a long time, inhibitory control was seen as the main process underlying self-control (Baumeister \& Heatherton, 1996; Hofmann, Friese, \& Strack, 2009). In other words, people with higher trait self-control were seen as being better at inhibiting current impulses through the use of their willpower, an effortful and potentially depleting process (Baumeister, Vohs, \& Tice, 2007). However, recent evidence suggests that effortful inhibition may not be the most important process behind self-control: Trait self-control neither correlates strongly with performance in laboratory tasks that require inhibitory control (Duckworth \& Kern, 2011; Saunders, Milyavskaya, Etz, Randles, \& Inzlicht, 2018) nor with the frequency by which people effortfully control their desires in daily life (Grund \& Carstens, 2019). Moreover, the frequency by which people feel that they effortfully control their desires in their daily lives is unrelated to goal attainment (Milyavskaya \& Inzlicht, 2017). In sum, trait self-control appears to support goalconsistent behavior through other processes than the effortful inhibition of impulses. It is therefore necessary that we broaden our view of the processes that underlie self-control (see also Converse, Juarez, \& Hennecke, 2019; Fujita, 2011; Milyavskaya, Berkman, \& De Ridder, 2019).

Here, we focus on one specific group of such processes that may underlie self-control, namely self-regulatory strategies. We base on the assumptions that people can intentionally deploy various strategies to promote their own goal pursuit, and that the effectiveness of these strategies is one key to successful self-control.

\section{1 | SELF-REGULATORY STRATEGIES}

Self-regulatory strategies can be defined as the "means through which individuals, in order to help themselves achieve their goals, actively alter their cognitive, motivational, affective, or behavioral reactions to a self-regulatory challenge" (Hennecke, Czikmantori, \& Brandstätter, 2019, p. 104). Strategies are anticipatory or preventive when they are used to avoid anticipated self-control conflicts. Someone who would like to increase their physical fitness may, for example, select a form of exercise that, despite not being the most effective one, is fun. In contrast, strategies are interventive when used to help dealing with or to attenuate an already present self-control conflict (see Fujita, 2011; Hofmann \& Kotabe, 2012). The person who exercises but feels like stopping may, for example, motivate themselves to persist by thinking of the positive consequences that they hope to attain through exercising.

A similar distinction characterizes strategies as either situational strategies, which aim at selecting and modifying one's circumstances to favor self-controlled behavior, and intrapsychic strategies, which refer to how people can use their attention, alter their cognitive interpretation of a given situation, or directly modulate their behavioral response to a given self-control conflict (Duckworth, Gendler, \& Gross, 2016). Choosing an exercise that is fun and for which little or no self-control is needed would qualify as a situational strategy. Reminding oneself of its benefits qualifies as an intrapsychic strategy.

Note that the deliberate use of self-regulatory strategies of any type is likely restricted to situations in which a person correctly identifies a self-control conflict and the need and possibility to strategically intervene. In particular, if a single unvirtuous act has negligible consequences for one's goal (eating one donut is not going to make you fat) and only its repetition becomes consequential, the identification of a self-control conflict, and, in turn, strategic attempts to avoid or deal with it may not occur (Fishbach \& Converse, 2011; Myrseth \& Fishbach, 2009). 
Let us emphasize that the idea that self-regulatory strategies can help people's self-control is not new. Research by Mischel (e.g., Mischel, 1974; Mischel, Shoda, \& Rodriguez, 1989), for example, has demonstrated that reappraisal (thinking differently about the temptation, for example, by imagining that a tempting marshmallow is a puffy white cloud rather than tasty candy) and distraction (e.g., by diverting one's attention away from the marshmallow) are effective self-regulatory strategies when dealing with a temptation. Kuhl (1983) has proposed so-called action control strategies of attention control (attending to goal-conducive information only), encoding control (encoding of goal-relevant information only), emotion control (putting oneself into a goal-conducive emotional state), motivation control (considering the positive incentives of a goal), and environmental control (removing distracting stimuli from one's environment). In addition, the literature on selfregulated learning (e.g., Boekaerts, 1997; Pintrich, 2000; Zimmerman, 1990, 2000) and other specialized applied literatures (e.g., on sports training, Green-Demers, Pelletier, Stewart, \& Gushue, 1998) have already proposed various self-regulatory strategies. Finally, the general self-regulation literature has investigated the effects of single strategies, like implementation intentions (Gollwitzer, 1999) or goal setting (Locke \& Latham, 2002, 2006) and attested to their effectiveness.

However, during the recent surge of interest in self-regulatory strategies, the focus has slightly shifted. For example, current research has become more interested in spontaneous strategy use in the complexity of daily life (as opposed to instructed strategy use or spontaneous strategy use in the lab, Friese \& Hofmann, 2016; Hennecke et al., 2019). Moreover, a new framework, the process model of self-regulation (Duckworth, Gendler, \& Gross, 2016) has been proposed that helps to organize different types of self-regulatory strategies.

\subsection{Strategies in the process model of self-regulation}

In this model (Duckworth, Gendler, \& Gross, 2016), strategies are organized along the different time points during an unfolding self-control conflict at which they can intervene: First, situation selection is the earliest strategy. It involves choosing situations that promote effective goal pursuit and avoiding situations during which self-control is needed or difficult (Duckworth, Gendler, \& Gross, 2016). The student who decides to study in the more pleasant environment of their dorm house's sunny backyard uses situation selection to support their persistence in studying. A dieter who decides that they should avoid walking home past their favorite bakery and rather chooses the path that does not offer such temptations, uses situation selection as well. Second, situation modification, another situational and preventive strategy, can be used to purposefully alter a situation to promote effective goal pursuit and reduce the need for self-control (Duckworth, Gendler, \& Gross, 2016). For example, a student may hide their cell phone in a drawer when studying to not get distracted by incoming messages. Or a person who has trouble getting out of bed may put the alarm clock at the other end of the bedroom and have it play the radio to help themselves actually get up on time. Third, people may use attentional deployment to direct their attention to aspects of the situation that will advance their goal pursuit/self-control and away from distractions, temptations, or other aspects of the situation that may undermine self-control (Duckworth, Gendler, \& Gross, 2016). Such attentional deployment is considered an intrapsychic strategy. For example, looking away from a delicious treat can help to not have a self-control conflict arise in the first place but it can also help to attenuate a conflict that has already emerged. Fourth, people may use cognitive change that alters the interpretation or understanding of a given situation (Duckworth, Gendler, \& Gross, 2016). A dieter who tries to think of a delicious treat primarily as a threat to their slim figure may, for example, support their self-control like this through cognitive change. Finally, response modulation is a strategy that through the suppression of undesired behaviors following from impulses or habits that conflict with the goal at hand, or the amplification of desired behaviors that advance the goal at hand.

\section{2 | Strategy effectiveness}

The process model is a useful framework that helps to categorize and theoretically distinguish different selfregulatory strategies. In our perspective, the model, however, does not yet capture a number of additional complexities that need to be considered when trying to identify effective self-regulatory strategies. 
First, in our view, the strategies in the framework (e.g., situation modification) should be seen as larger categories that encompass a multitude of more specific strategies. In a study by Hennecke et al. (2019), participants reported strategies such as changing the aversive activity itself, changing the environment in which it is performed, reducing distractions, seeking social support, taking a substance, and task enrichment which all modify the situation when people experience that they no longer feel like persisting in a goal-conducive but aversive activity. Figure 1 shows these and other strategies that participants reported in this study within the categories of the process model of self-regulation. Table 1 provides more detailed information on each of them. (Note that, in this study, situation selection strategies were not assessed, given that participants were asked to report how they dealt with an already present self-control conflict).

Second, in their discussion of strategy effectiveness, Duckworth, Gendler, \& Gross, 2016 and Duckworth, White, et al., 2016 propagate that earlier strategies, that is, strategies that prevent self-control conflicts or intervene early during their emergence, should be more effective than later strategies that deal with an already emerged self-control conflict. Indeed, Duckworth, White, et al. (2016) report in two studies, that students who were instructed to use

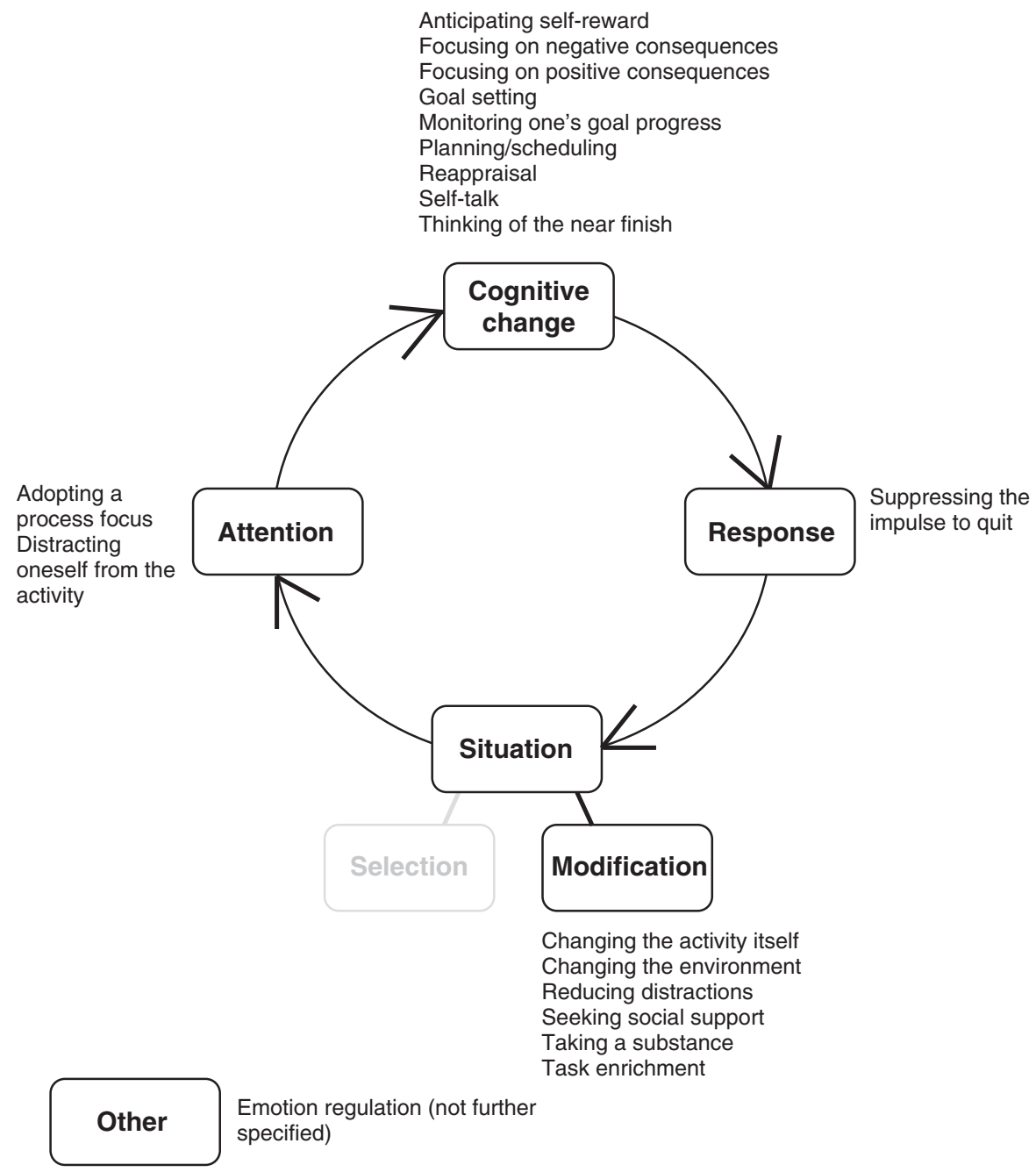

FIGURE 1 Assignment of strategies to categories of self-regulatory strategies in Duckworth, Gendler, and Gross's (2016) process model of self-regulation (Hennecke et al., 2019, with permission from John Wiley \& Son) 


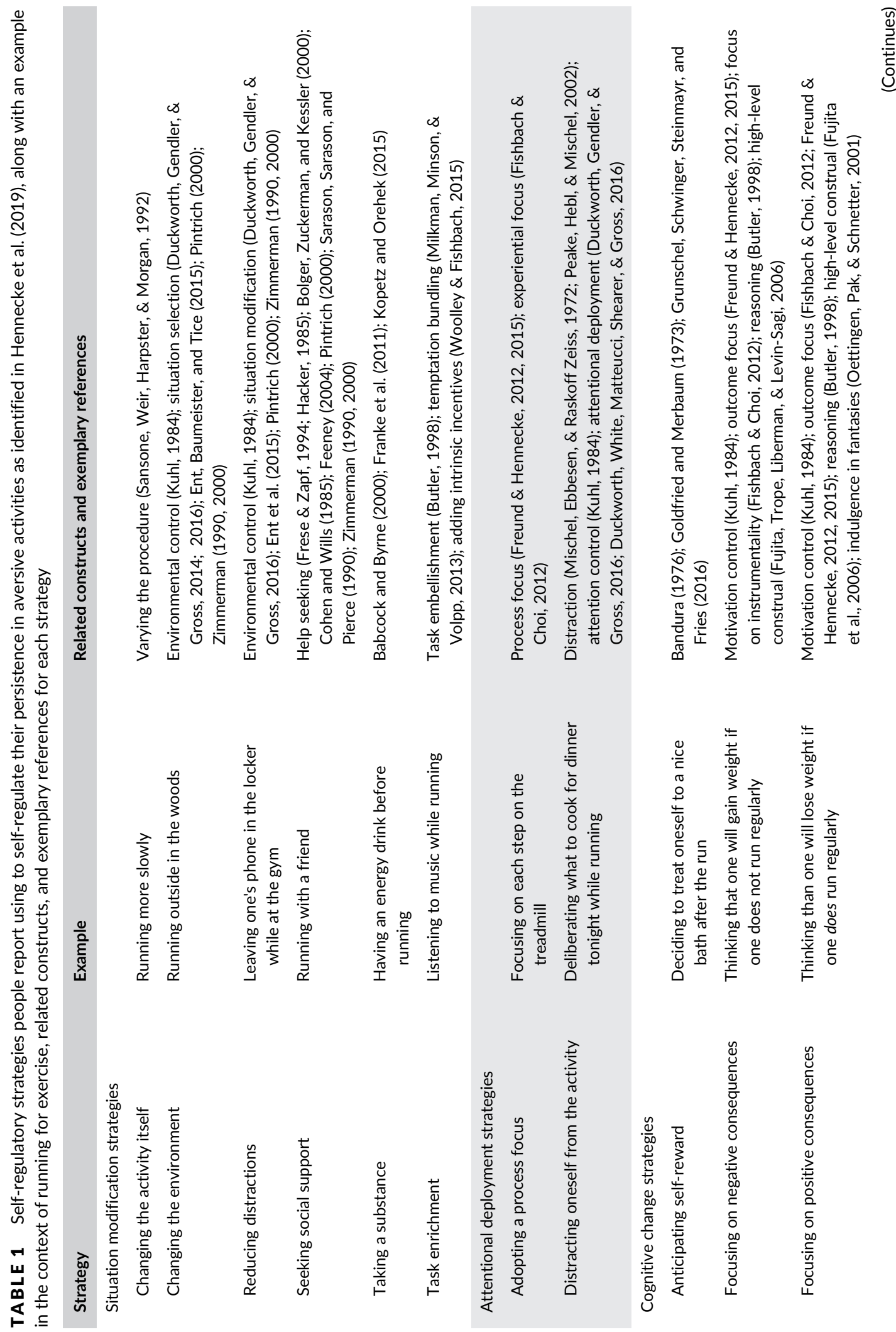




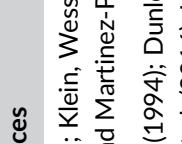

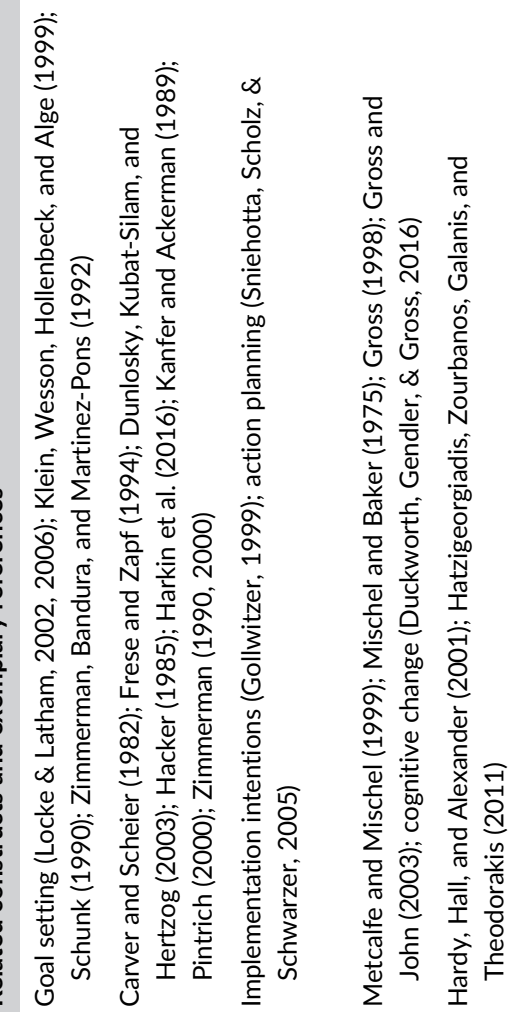

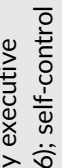

这

눙

ह

高

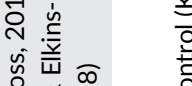

क

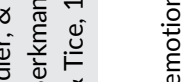

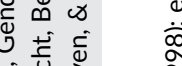

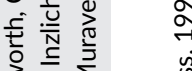

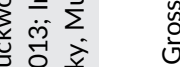

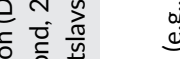

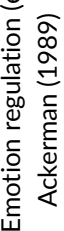

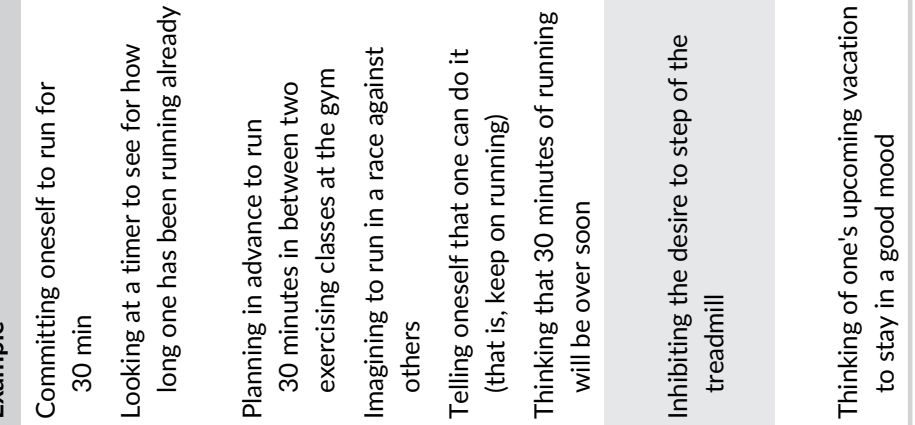

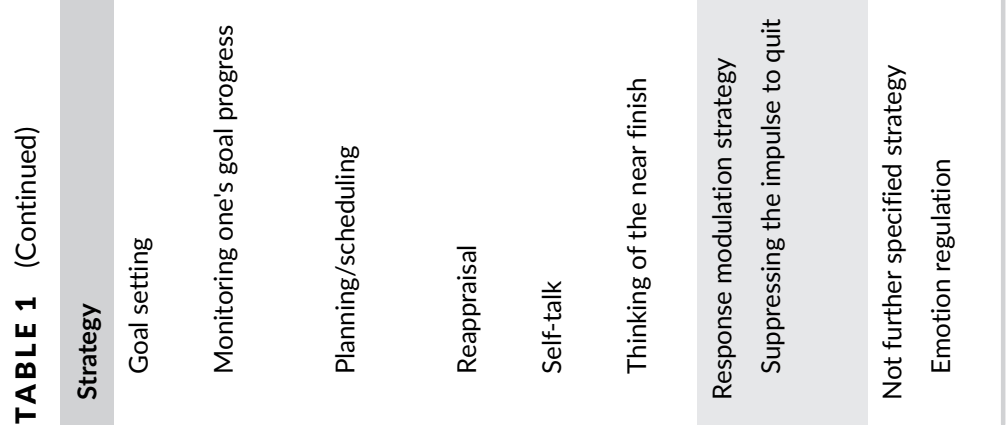


situation modification by removing "temptations from sight rather than to resist them directly" (p. 335) were more successful in meeting their academic goals in the subsequent week than students who were instructed to use response modulation by "resisting temptation whenever they encounter them" (p. 335). In turn, students who used response modulation were no more successful than students who were not instructed to use any strategy. Given that, however, there are various specific self-regulatory strategies within each category or stage of the self-control conflict, we think that it is probably more accurate to infer from these studies that some earlier strategies are more effective than some later strategies. This is backed up by another experience sampling study (Hennecke et al., 2019) in which participants reported which of the various specific strategies they had used in a recent self-control conflict and the extent to which they were successful in resolving the conflict. In this study, some earlier strategies like situation modification through task enrichment or attentional deployment through distracting oneself from the (aversive) activity were without effect or even maladaptive, respectively. In contrast, some specific cognitive change strategies were-despite being relatively late strategies-positively related to self-regulatory success, namely focusing on the positive consequences of performing the activity, monitoring one's progress, and thinking of the near finish. Accordingly, we believe that the claim that earlier strategies are more effective strategies in general-irrespective of the specific type of strategy and the situation for which it is used-requires further evidence.

Third, and also following from the previous point, we think the assumption that any given strategy is per se more effective than a given other one, is probably an oversimplification anyway (see "fallacy of uniform efficacy," Bonanno \& Burton, 2013). It misses that the effectiveness of any given strategy likely depends on various other factors, for example, the characteristics of the self-control conflict at hand (e.g., its demands), the person and their characteristics, as well as the current goal. We will turn to an extensive discussion of these ideas and the role of regulatory flexibility in strategy use later.

Another interesting question concerns the definition of strategy effectiveness. Defining the circumstances under which we consider strategies as effective (or not), is a task with high relevance for designing future interventions capitalizing on self-regulatory strategy deployment. In our view, the effectiveness of any strategy can be measured with several different criteria. In the previous section, we have discussed effectiveness as success with regard to a current self-control conflict (Hennecke et al., 2019). Does a given preventive strategy indeed enable the person to avoid an otherwise daunting self-control conflict? Does a strategy enable the person to initiate an unpleasant or effortful task instead if procrastinating it or does it enable the person to continue with it for longer or, ideally, until its completion? The effects of a strategy on subsequent success may be driven by a number of processes: This may include, for example, making a temptation less tempting (e.g., through reappraisal, see Mischel \& Baker, 1975), making an otherwise aversive activity more enjoyable (e.g., through a focus on the process itself, Fishbach \& Choi, 2012), or by making the goals of an activity more salient (like "focusing on the positive consequences," Hennecke et al., 2019, but see Fishbach \& Choi, 2012).

Another possible criterion is long-term success with regard to a goal at hand. Many goals cannot be pursued in just one behavioral episode but require repeated engagement in various goal-directed activities across situations, for example, preparing for an exam, or controlling one's body weight (Moshontz \& Hoyle, 2019). Accordingly, a strategy's effectiveness can also be evaluated with regard to its ability to help the person maintain goalconsistent behavior over time. One relevant discussion in this regard refers to whether self-control resembles a limited resource that is depleted through the use of effortful inhibition (e.g., Carter \& McCullough, 2014; Friese, Loschelder, Gieseler, Frankenbach, \& Inzlicht, 2019; Hagger et al., 2016; Lurquin \& Miyake, 2017). While the idea is highly debated, there is some evidence that at least the subjective feeling of depletion after exerting selfcontrol may cause shifts in motivation and attention toward taking a break from further goal pursuit (Clarkson, Hirt, Jia, \& Alexander, 2010; Inzlicht \& Schmeichel, 2012; Job, Bernecker, Miketta, \& Friese, 2015). A strategy that can circumvent the need for effortful inhibition, for example, because it prevents self-control conflicts from occurring in the first place or attenuates their intensity (e.g., by making an activity more enjoyable), bears a high potential for also supporting long-term goal pursuit over time by making such shifts away from current goals be less likely. 
Despite having effects on the focal outcome, that is, whether people show goal-consistent behavior or not, selfregulatory strategies may also vary with regard to their effects on the person's well-being. Generally, self-control is positively related to well-being, and likely so because people with higher self-control experience less conflicts between their current desires and their goals (Hofmann et al., 2014; Wiese et al., 2017). Another possible path through which self-control may lead to higher well-being is through its positive effect on goal progress (Brunstein, 1993). Accordingly, strategies that make self-control easier (e.g., an aversive activity more fun) and/or strategies that (thereby) advance goal progress may also have beneficial effects on individuals' well-being. In fact, Nielsen, Gwozdz, and de Ridder (2019) report positive effects on subjective well-being for attentional deployment and reappraisal (but note their somewhat different operationalization of these strategies). Inhibition, in contrast, was negatively related to subjective well-being. This is in line with the interpretation that inhibition does not reduce the experience of conflict between goals and impulses (Nielsen et al., 2019).

\section{2 | INDIVIDUAL DIFFERENCES IN STRATEGY USE}

It seems plausible that individuals who are high in trait self-control should also have an inclination to use, particularly effective strategies. Indeed, participants with higher trait self-control focus more frequently on the positive consequences of an activity, set goals, and regulate their emotions (Hennecke et al., 2019). All these strategies appear to have positive effects on self-regulation, in terms of both success in a given self-control conflict and goal attainment (Hennecke et al., 2019; Klein et al., 1999; Locke \& Latham, 2002, 2006; Zimmerman et al., 1992). People with high levels of trait self-control furthermore report a stronger tendency to avoid being confronted with temptations than people with lower levels of trait self-control (Ent et al., 2015; Nielsen et al., 2019), a strategy that in a different study had positive consequences for goal attainment (Duckworth, White, et al., 2016). People with high levels of trait selfcontrol moreover tend to also use more attentional deployment (although here, strategies were operationalized in a somewhat different way, sample item: "When I am trying to focus my attention, I am easily distracted," recoded), reappraisal ("I control my emotions by changing the way I think about the situation I am in."), and inhibition (sample item: "It is easy for me to inhibit fun behavior that would be inappropriate.") (Nielsen et al., 2019).

While trait self-control may promote the use of self-regulatory strategies, and probably specifically of effective ones, Friese and Hofmann (2016) have investigated a state, namely state mindfulness, as a potential negative predictor of strategy use. Mindfulness can be understood as a state in which of "pronounced awareness of one's moment-to-moment experiences in a nonjudgmental and accepting way" (Friese \& Hofmann, 2016, p. 1). To resist temptations, people in a state of higher mindfulness were less likely to use four different types of strategies, namely to suppress thoughts and feelings about the desire, to try to stop themselves from giving in to the desire, to distract themselves, and to avoid the things, people, and situations that gave rise to the desire. The authors suggest that the fact that mindful people are less inclined to strategically control their desires might follow from their heightened state of acceptance toward these desires, which should, in turn, reduce the motivation to resist them.

\section{3 | STRATEGY EFFECTIVENESS AS A FUNCTION OF CONTEXT}

In the field of emotion regulation and coping, Bonanno and Burton (2013) coined the term fallacy of uniform efficacy. It describes the misguided tendency of researchers to assume that certain emotion regulation strategies are, inherently and across situations, adaptive, whereas others are, inherently and across situations, maladaptive. For example, the former perspective that problem-focused coping strategies are generally more adaptive than emotion-focused coping strategies (Kohn, 1996) had to be revised, given the evidence that problem-focused coping is helpful when dealing with controllable stressors but potentially harmful when dealing with uncontrollable stressors (Aldrige \& 
Roesch, 2007; Clarke, 2006) and findings showing that in certain situations, for example, when individuals deal with breast cancer or chronic pain, emotion-focused coping can be adaptive and lead to lower levels of pain and depressive symptoms (Austenfeld \& Stanton, 2004).

Transferred to self-control conflicts, this implies that any given self-regulatory strategy may-even when the same outcome is considered-be effective in one context but not in another. Determining the decisive characteristics of context that may render a strategy as more or less effective appears like a fruitful avenue for future research. At this point, we can only offer some ideas. We propose that situational demands, individual characteristics, and goal characteristics may moderate strategy effectiveness.

\section{1 | Situational demands}

Self-control conflicts vary with regard to the demands they pose. For example, persistence may require self-control when the goal-directed activity is experienced as mentally effortful, as boring, as physically effortful, or as emotionally draining (Hennecke et al., 2019). What type of demands are experienced and to what extent may be important to consider. If, for example, a person already experiences high mental effort during a task, a strategy that imposes additional cognitive load (e.g., monitoring one's goal progress) may be maladaptive. A challenging strategy may, however, render an otherwise boring activity more interesting (Sansone et al., 1992). This idea is supported by findings from research on self-regulated learning, where self-monitoring has shown to be less helpful during complex (as opposed to simple) tasks, where it significantly decreases performance through increasing cognitive load (Van Gog, Kester, \& Paas, 2011).

\section{2 | Individual characteristics}

There is also a strong possibility that individual differences can moderate the effectiveness of certain strategies. A self-regulatory strategy that demands mental effort may be more suitable to individuals with higher working memory capacity but ill-suited for individuals with low working-memory capacity (Hofmann, Gschwendner, Friese, Wiers, \& Schmitt, 2008). Similarly, interventive strategies that deal with an already evolved self-control conflict may be difficult to successfully implement for individuals with low levels of self-control or high levels of impulsivity. They may, however, benefit from preventive or situational strategies that help them avoid self-control conflicts in the first place. Indeed, one study found that individual differences in eating self-control moderated the effectiveness of two self-regulatory strategies: Moderation (eating a smaller, predetermined amount of something unhealthy) was more effective than avoidance (completely avoiding the unhealthy food) only for people high in self-control (Haws, Lamberton, Dzhogleva, \& Fitzsimons, 2011).

\section{3 | Goal characteristics}

Finally, the characteristics of the goal that is currently pursued may moderate a given strategy's effectiveness. Goals differ from each other on various dimensions (Ryan, Sheldon, Kasser, \& Deci, 1996), such as their orientation toward approach or avoidance (e.g., Elliot \& McGregor, 1999). Generally, the principle of regulatory fit (Hennecke, 2019; Higgins, 2000; Higgins \& Spiegel, 2004) may be applicable, according to which regulatory success depends on how well a given means (here: self-regulatory strategy) fits a given goal (or goal pursuer's) characteristics. It seems plausible, for example, that an approach goal unfolds stronger motivational impetus when its pursuer thinks, during a selfcontrol conflict, strategically of its positive consequences, whereas an avoidance goal may unfold stronger motivational impetus when its pursuer strategically thinks of its negative consequences. 


\section{4 | REGULATORY FLEXIBILITY}

Given that strategy effectiveness may be highly context-dependent, regulatory flexibility, that is, people's ability to flexibly adapt their strategy use across different contexts, may be a key to successful self-control. Regulatory flexibility may entail at least three aspects: (a) Context-sensitivity, (b) strategy repertoire, and (c) feedback (Bonanno \& Burton, 2013).

Context-sensitivity can be understood as evaluating the impinging demands and opportunities of a situational context and choosing the most effective regulatory strategy fitting that context (Bonanno \& Burton, 2013). We are not aware of any research looking directly at individual differences in context-sensitivity during self-control conflicts (but see evidence for the role of context-sensitivity in research on emotion regulation and coping, Burton \& Bonanno, 2016; Chen, Chen, \& Bonanno, 2018; Levy-Gigi et al., 2016; Rodin et al., 2017). However, given that strategy use during self-control conflicts varies as a function of the demands experienced during the task (physical effort, mental effort, emotional challenge, and boredom; Hennecke et al., 2019), people appear to display some contextsensitivity in general. For example, participants were less likely to enrich mentally effortful tasks with something pleasant or to distract themselves from mentally effortful tasks, whereas they were more likely to use task enrichment or distraction during boring tasks.

In addition to context-sensitivity, a sufficiently large strategy repertoire should be required for regulatory flexibility. In line with this, research in the field of coping and emotion regulation shows that a larger repertoire of coping-strategies is associated with less stress resulting from marital strain (Pearlin \& Schooler, 1978) and with lower levels of depression resulting from life event-related stress (Lam \& McBride-Chang, 2007).

Finally, the ability to monitor feedback about the effectiveness of a strategy used, and to maintain, end, or change the strategy based on information gathered from self-monitoring represents another important component of regulatory flexibility (Bonanno \& Burton, 2013). Indeed, a meta-analysis has shown that self-monitoring is associated with goal progress (Harkin et al., 2016).

\section{5 | OUTLOOK: FUTURE RESEARCH AND APPLICATION}

A recent surge in interest on self-regulatory strategies in daily life has just begun. Accordingly, there are many unanswered questions. Future research should try to rely less on self-reported success criteria (Duckworth, Gendler, \& Gross, 2016; Hennecke et al., 2019) but widen criteria (e.g., to include well-being) and assess actual goal progress and attainment as additional outcomes of strategy use. However, assessing strategy use differently than through self-report may prove difficult, given that many strategies are intrapsychic and any given behavior might be difficult to interpret as strategy use from the outside.

Overall, it is advisable to further consider the variety of potential self-regulatory strategies and their effects on self-control in orchestration. It will be particularly informative to investigate under which contextual conditions and for whom certain strategies are effective on the long run. Relating flexibility to trait self-control and success in daily self-control conflicts could be another piece of the puzzle that helps us understand how trait self-control "gets outside the skin."

Findings from such research could furthermore be of great importance for the design of interventions, allowing researchers and practitioners to more accurately tailor the right self-regulatory strategy to both the person using it and the situation it is used in.

\section{ACKNOWLEDGMENTS}

The preparation of this article has been supported by a grant from the Swiss National Science Foundation (Grant \# 100019_179207) awarded to Marie Hennecke. The authors thank Christoph Schild for his comments on the manuscript. 


\section{ORCID}

Marie Hennecke (D) https://orcid.org/0000-0002-0263-4598

\section{FURTHER READING}

Aldao, A. (2013). The future of emotion regulation research: Capturing context. Perspectives on Psychological Science, 8, 155-172. https://doi.org/10.1177/1745691612459518

Hofmann, W., Baumeister, R. F., Förster, G., \& Vohs, K. D. (2012). Everyday temptations: An experience sampling study of desire, conflict, and self-control. Journal of Personality and Social Psychology, 102, 1318-1335. https://doi.org/10.1037/ a0026545

Hoyle, R. H., \& Davisson, E. K. (2016). Varieties of self-control and their personality correlates. In K. D. Vohs \& R. F. Baumeister (Eds.), Handbook of self-regulation: Research, theory, and application (3rd ed., pp. 396-413). New York, NY: Guilford Press.

Milyavskaya, M., Inzlicht, M., Hope, N., \& Koestner, R. (2015). Saying 'no' to temptation: Want-to motivation improves selfregulation by reducing temptation rather than by increasing self-control. Journal of Personality and Social Psychology, 109, 677-693. https://doi.org/10.1037/pspp0000045

Sheppes, G., Scheibe, S., Suri, G., Radu, P., Blechert, P., \& Gross, J. J. (2014). Emotion regulation choice: A conceptual framework and supporting evidence. Journal of Experimental Psychology: General, 143, 163-181. https://doi.org/10.1037/ a0030831

Tamir, M. (2009). What do people want to feel and why?: Pleasure and utility in emotion regulation. Current Directions in Psychological Science, 18, 101-105. https://doi.org/10.1111/j.1467-8721.2009.01617.x

\section{REFERENCES}

Aldrige, A. A., \& Roesch, S. C. (2007). Coping and adjustment in children with cancer: A meta-analytic study. Journal of Behavioral Medicine, 30, 115-129. https://doi.org/10.1007/s10865-006-9087-y

Austenfeld, J. L., \& Stanton, A. L. (2004). Coping through emotional approach: A new look at emotion, coping, and healthrelated outcomes. Journal of Personality, 72, 1335-1364. https://doi.org/10.1111/j.1467-6494.2004.00299.x

Babcock, Q., \& Byrne, T. (2000). Student perceptions of methylphenidate abuse at a public liberal arts college. Journal of American College Health, 49, 143-145. https://doi.org/10.1080/07448480009596296

Bandura, A. (1976). Self-reinforcement: Theoretical and methodological considerations. Behavior, 4, 135-155.

Baumeister, R. F., Bratslavsky, E., Muraven, M., \& Tice, D. M. (1998). Ego depletion: Is the active self a limited resource? Journal of Personality and Social Psychology, 74, 1252-1265.

Baumeister, R. F., \& Heatherton, T. F. (1996). Self-regulation failure: An overview. Psychological Inquiry, 7, 1-15. https://doi. org/10.1207/s15327965pli0701_1d

Baumeister, R. F., Vohs, K. D., \& Tice, D. M. (2007). The strength model of self-control. Current Directions in Psychological Science, 16, 351-355. https://doi.org/10.1111/j.1467-8721.2007.00534.x

Boekaerts, M. (1997). Self-regulated learning: A new concept embraced by researchers, policy makers, educators, teachers, and students. Learning and Instruction, 7, 161-186. https://doi.org/10.1016/s0959-4752(96)00015-1

Bolger, N., Zuckerman, A., \& Kessler, R. C. (2000). Invisible support and adjustment to stress. Journal of Personality and Social Psychology, 79, 953-961. https://doi.org/10.1037/0022-3514.79.6.953

Bonanno, G. A., \& Burton, C. L. (2013). Regulatory flexibility: An individual differences perspective on coping and emotion regulation. Perspectives on Psychological Science, 8, 591-612. https://doi.org/10.1177/1745691613504116

Brunstein, J. C. (1993). Personal goals and subjective well-being: A longitudinal study. Journal of Personality and Social Psychology, 65, 1061-1070. https://doi.org/10.1037//0022-3514.65.5.1061

Burton, C. L., \& Bonanno, G. A. (2016). Measuring ability to enhance and suppress emotional expression: The flexible regulation of emotional expression (FREE) scale. Psychological Assessment, 28, 929-941. https://doi.org/10.1037/pas0000231

Butler, D. (1998). The strategic content learning approach to promoting self-regulated learning: A report of three studies. Journal of Educational Psychology, 90, 682-697. https://doi.org/10.1037/0022-0663.90.4.682

Carter, E. C., \& McCullough, M. E. (2014). Publication bias and the limited strength model of self-control: Has the evidence for ego depletion been overestimated? Frontiers in Psychology, 5, 1-11. https://doi.org/10.3389/fpsyg.2014.00823

Carver, C. S. (2019). Personality. In E. J. Finkel \& R. F. Baumeister (Eds.), Advanced social psychology: The state of the science (2nd ed., pp. 471-498). New York, NY: Oxford University Press.

Carver, C. S., \& Scheier, M. F. (1982). Control theory: A useful conceptual framework for personality-social, clinical, and health psychology. Psychological Bulletin, 92, 111-135. https://doi.org/10.1037/0033-2909.92.1.111

Chen, S., Chen, T., \& Bonanno, G. A. (2018). Expressive flexibility: Enhancement and suppression abilities differentially predict life satisfaction and psychopathology symptoms. Personality and Individual Differences, 126, 78-84. https://doi.org/ 10.1016/j.paid.2018.01.010 
Clarke, A. T. (2006). Coping with interpersonal stress and psychosocial health among children and adolescents: A meta-analysis. Journal of Youth and Adolescence, 35, 11-24. https://doi.org/10.1007/s10964-005-9001-x

Clarkson, J. J., Hirt, E. R., Jia, L., \& Alexander, M. B. (2010). When perception is more than reality: The effects of perceived versus actual resource depletion on self-regulatory behavior. Journal of Personality and Social Psychology, 98, 29-46. https://doi.org/10.1037/a0017539

Cohen, S., \& Wills, T. A. (1985). Stress, social support, and the buffering hypothesis. Psychological Bulletin, 98, 310-257. https://doi.org/10.1037/0033-2909.98.2.310

Converse, B. A., Juarez, L., \& Hennecke, M. (2019). Self-control and the reasons behind our goals. Journal of Personality and Social Psychology, 116, 860-883. https://doi.org/10.1037/pspp0000188

De Ridder, D. T. D., Lensvelt-Mulders, G., Finkenauer, C., Stok, F. M., \& Baumeister, R. F. (2012). Taking stock of self-control: A meta-analysis of how trait self-control relates to a wide range of behaviors. Personality and Social Psychology Review, 16, 76-99. https://doi.org/10.1177/1088868311418749

Diamond, A. (2013). Executive functions. Annual Review of Psychology, 64, 135-168. https://doi.org/10.1146/annurevpsych-113011-143750

Duckworth, A. L., Gendler, T. S., \& Gross, J. J. (2014). Self-control in school-age children. Educational Psychologist, 49, 199-217.

Duckworth, A. L., Gendler, T. S., \& Gross, J. J. (2016). Situational strategies for self-control. Perspectives on Psychological Science, 11, 35-55. https://doi.org/10.1177/1745691615623247

Duckworth, A. L., \& Kern, M. L. (2011). A meta-analysis of the convergent validity of self-control measures. Journal of Research in Personality, 45, 259-268. https://doi.org/10.1016/j.jrp.2011.02.004

Duckworth, A. L., White, R. E., Matteucci, A. J., Shearer, A., \& Gross, J. J. (2016). A stitch in time: Strategic self-control in high school and college students. Journal of Educational Psychology, 108, 329-341. https://doi.org/10.1037/ edu0000062

Dunlosky, J., Kubat-Silam, A. K., \& Hertzog, C. (2003). Training monitoring skills improves older adults' self-paced associative learning. Psychology and Aging, 18, 340-345. https://doi.org/10.1037/0882-7974.18.2.340

Elliot, A. J., \& McGregor, H. A. (1999). Test anxiety and the hierarchical model of approach and avoidance achievement motivation. Journal of Personality and Social Psychology, 76, 628-519. https://doi.org/10.1037/0022-3514.76.4.628

Ent, M. R., Baumeister, R. F., \& Tice, D. M. (2015). Trait self-control and the avoidance of temptation. Personality and Individual Differences, 74, 12-15. https://doi.org/10.1016/j-paid.2014.09.031

Feeney, B. C. (2004). A secure base: Responsive support of goal strivings and exploration in adult intimate relationships. Journal of Personality and Social Psychology, 87, 631-648. https://doi.org/10.1037/e633872013-126

Fishbach, A., \& Choi, J. (2012). When thinking about goals undermines goal pursuit. Organizational Behavior and Human Decision Processes, 118, 99-107. https://doi.org/10.1016/j.obhdp.2012.02.003

Fishbach, A., \& Converse, B. A. (2011). Identifying and battling temptation. In K. D. Vohs \& R. F. Baumeister (Eds.), Handbook of self-regulation: Research, theory, and applications (2nd ed., pp. 244-262). New York, NY: Guilford Press.

Franke, A. G., Bonertz, C., Christmann, M., Huss, M., Fellgiebel, A., Hildt, E., \& Lieb, K. (2011). Non-medical use of prescription stimulants and illicit use of stimulants for cognitive enhancement in pupils and students in Germany. Pharmacopsychiatry, 44, 60-66. https://doi.org/10.1055/s-0030-1268417

Frese, M., \& Zapf, D. (1994). Action as the core of work psychology: A German approach. In H. C. Triandis, M. D. Dunnette, \& L. M. Hough (Eds.), Handbook of industrial and organizational psychology (Vol. 4, 2nd, pp. 271-340). Palo Alto, CA: Consulting Psychologists Press.

Freund, A. M., \& Hennecke, M. (2012). Changing eating behaviour vs. losing weight: The role of goal focus for weight loss in overweight women. Psychology and Health, 7, 25-42. https://doi.org/10.1080/08870446.2011.570867

Freund, A. M., \& Hennecke, M. (2015). On means and ends: The role of goal focus in successful goal pursuit. Current Directions in Psychological Science, 24, 149-153. https://doi.org/10.1177/0963721414559774

Friese, M., \& Hofmann, W. (2016). State mindfulness, self-regulation, and emotional experience in everyday life. Motivation Science, 2, 1-14. https://doi.org/10.1037/mot0000027

Friese, M., Loschelder, D. D., Gieseler, K., Frankenbach, J., \& Inzlicht, M. (2019). Is ego depletion real? An analysis of arguments. Personality and Social Psychology Review, 23, 107-131. https://doi.org/10.1177/1088868318762183

Fujita, K. (2011). On conceptualizing self-control as more than the effortful inhibition of impulses. Personality and Social Psychology Review, 15, 352-366. https://doi.org/10.1177/1088868311411165

Fujita, K., Trope, Y., Liberman, N., \& Levin-Sagi, M. (2006). Construal levels and self-control. Journal of Personality and Social Psychology, 90, 351-367. https://doi.org/10.1037/0022-3514.90.3.351

Goldfried, M. R., \& Merbaum, M. (1973). Behavior change through self-control. New York, NY: Holt, Rinehart and Winston.

Gollwitzer, P. M. (1999). Implementation intentions: Strong effects of simple plans. American Psychologist, 54, 493-503. https://doi.org/10.1037/0003-066x.54.7.493 
Green-Demers, I., Pelletier, L. G., Stewart, D. G., \& Gushue, N. R. (1998). Coping with the less interesting aspects of training: Toward a model of interest and motivation enhancement in individual sports. Basic and Applied Social Psychology, 20, 251-261. https://doi.org/10.1207/15324839851036598

Gross, J. J. (1998). The emerging field of emotion regulation: An integrative review. Review of General Psychology, 2, 271-299. https://doi.org/10.1037/1089-2680.2.3.271

Gross, J. J., \& John, O. P. (2003). Individual differences in two emotion regulation processes: Implications for affect, relationships, and well-being. Journal of Personality and Social Psychology, 85, 348-362. https://doi.org/10.1037/0022-3514.85. 2.348

Grund, A., \& Carstens, C. (2019). Self-control motivationally reconsidered: 'Acting' self-controlled is different to 'being good' at self-control. Motivation and Emotion, 43, 63-81. https://doi.org/10.1007/s11031-018-9721-3

Grunschel, C., Schwinger, M., Steinmayr, R., \& Fries, S. (2016). Effects of using motivational regulation strategies on students' academic procrastination, academic performance, and well-being. Learning and Individual Differences, 49, 162-170. https://doi.org/10.1016/j.lindif.2016.06.008

Hacker, W. (1985). Activity: A fruitful concept in industrial psychology. In M. Frese \& J. Sabini (Eds.), Goal directed behavior: The concept of action in psychology (pp. 262-284). Hillsdale, NJ: Erlbaum.

Hagger, M. S., Chatzisarantis, N. L. D., Alberts, H., Anggono, C. O., Batailler, C., Birt, A., ... Zwienenberg, M. (2016). A multilab preregistered replication of the ego-depletion effect. Perspectives on Psychological Science, 11, 546-573. https://doi.org/ $10.1177 / 1745691616652873$

Hampson, S. E. (2012). Personality processes: Mechanisms by which personality traits 'get outside the skin'. Annual Review of Psychology, 63, 315-339. https://doi.org/10.1146/annurev-psych-120710-100419

Hardy, J., Hall, C. R., \& Alexander, M. R. (2001). Exploring self-talk and affective states in sport. Journal of Sports Sciences, 19, 469-475. https://doi.org/10.1080/026404101750238926

Harkin, B., Webb, T. L., Chang, B. P. I., Prestwich, A., Conner, M., Kellar, I., ... Sheeran, P. (2016). Does monitoring goal progress promote goal attainment? A meta-analysis of the experimental evidence. Psychological Bulletin, 142, $198-229$. https://doi.org/10.1037/bul0000025

Hatzigeorgiadis, A., Zourbanos, N., Galanis, E., \& Theodorakis, Y. (2011). Self-talk and sports performance: A meta-analysis. Perspectives on Psychological Science, 6, 348-356. https://doi.org/10.1177/1745691611413136

Haws, K., Lamberton, C., Dzhogleva, H., \& Fitzsimons, G. (2011). A life in balance or a slippery slope?: Exploring the use and effectiveness of moderation versus avoidance self-control strategies. Advances in Consumer Research, 39, 27-28.

Hennecke, M. (2019). What doesn't kill you...: Means for avoidance goal pursuit are less enjoyable than means for approach goal pursuit. Motivation Science, 5, 1-13. https://doi.org/10.1037/mot0000104

Hennecke, M., Czikmantori, T., \& Brandstätter, V. (2019). Doing despite disliking: Self-regulatory strategies in everyday aversive activities. European Journal of Personality, 33, 104-128. https://doi.org/10.1002/per.2182

Higgins, E. T. (2000). Making a good decision: Value from fit. American Psychologist, 55, 1217-1230. https://doi.org/10. 1037/0003-066X.55.11.1217

Higgins, E. T., \& Spiegel, S. (2004). Promotion and prevention strategies for self-regulation. In R. F. Baumeister \& K. D. Vohs (Eds.), Handbook of self-regulation: Research, theory, and applications (pp. 171-187). New York: The Guilford Press.

Hofmann, W., Friese, M., \& Strack, F. (2009). Impulse and self-control from a dual-systems perspective. Perspectives on Psychological Science, 4, 162-176. https://doi.org/10.1111/j.1745-6924.2009.01116.x

Hofmann, W., Gschwendner, T., Friese, M., Wiers, R. W., \& Schmitt, M. (2008). Working memory capacity and selfregulatory behavior: Toward an individual-differences perspective on behavior determination by automatic versus controlled processes. Journal of Personality and Social Psychology, 95, 962-977. https://doi.org/10.1037/a0012705

Hofmann, W., \& Kotabe, H. (2012). A general model of preventive and interventive self-control. Social and Personality Psychology Compass, 6, 707-722. https://doi.org/10.1111/j.1751-9004.2012.00461.x

Hofmann, W., Luhmann, M., Fisher, R. R., Vohs, K. D., \& Baumeister, R. F. (2014). Yes, but are they happy? Effects of trait self-control on affective well-being and life satisfaction. Journal of Personality, 82, 265-277. https://doi.org/10.1111/ jopy. 12050

Inzlicht, M., Berkman, E., \& Elkins-Brown, N. (2016). The neuroscience of "ego depletion" or: How the brain can help us understand why self-control seems limited. In E. Harmon-Jones \& M. Inzlicht (Eds.), Social neuroscience: Biological approaches to social psychology (pp. 101-123). New York, NY: Routledge.

Inzlicht, M., \& Schmeichel, B. J. (2012). What is ego depletion? Toward a mechanistic revision of the resource model of selfcontrol. Perspectives on Psychological Science, 7, 450-463. https://doi.org/10.1177/1745691612454134

Job, V., Bernecker, K., Miketta, S., \& Friese, M. (2015). Implicit theories about willpower predict the activation of a rest goal following self-control exertion. Journal of Personality and Social Psychology, 109, 694-706. https://doi.org/10.1037/ pspp0000042

Kanfer, R., \& Ackerman, P. L. (1989). Motivation and cognitive abilities: An integrative/aptitude-treatment interaction approach to skill acquisition. Journal of Applied Psychology, 74, 657-690. https://doi.org/10.1037/0021-9010.74.4.657 
Klein, H. J., Wesson, M. J., Hollenbeck, J. R., \& Alge, B. J. (1999). Goal commitment and the goal setting process: Conceptual clarification and empirical synthesis. Journal of Applied Psychology, 84, 885-896. https://doi.org/10.1037//0021-9010. 84.6.885

Kohn, P. M. (1996). On coping adaptively with daily hassles. In M. Zeidner \& N. S. Endler (Eds.), Handbook of coping: Theory, research, applications (pp. 181-201). New York: Wiley.

Kopetz, C., \& Orehek, E. (2015). When the end justifies the means: Self-defeating behaviors as "rational" and "successful" self-regulation. Current Directions in Psychological Science, 24, 386-391. https://doi.org/10.1177/0963721415589329

Kuhl, J. (1983). Motivation, Konflikt und Handlungskontrolle. [Motivation, conflict, and action control]. Berlin, Germany: Springer.

Kuhl, J. (1984). Volitional aspects of achievement motivation and learned helplessness: Toward a comprehensive theory of action control. Progress in Experimental Personality Research, 13, 99-171. https://doi.org/10.1016/b978-0-12-5414135.50007-3

Lam, C. B., \& McBride-Chang, C. A. (2007). Resilience in young adulthood: The moderating influences of gender-related personality traits and coping flexibility. Sex Roles, 56, 159-172. https://doi.org/10.1007/s11199-006-9159-z

Levy-Gigi, E., Bonanno, G. A., Shapiro, A. R., Richter-Levin, G., Kéri, S., \& Sheppes, G. (2016). Emotion regulatory flexibility sheds light on the elusive relationship between repeated traumatic exposure and posttraumatic stress disorder symptoms. Clinical Psychological Science, 4, 28-39. https://doi.org/10.1177/2167702615577783

Locke, E. A., \& Latham, G. P. (2002). Building a practically useful theory of goal setting and task motivation: A 35-year odyssey. American Psychologist, 57, 705-717. https://doi.org/10.1037/0003-066X.57.9.705

Locke, E. A., \& Latham, G. P. (2006). New directions in goal-setting theory. Current Directions in Psychological Science, 15, 265-268. https://doi.org/10.1111/j.1467-8721.2006.00449.x

Lurquin, J. H., \& Miyake, A. (2017). Challenges to ego-depletion research go beyond the replication crisis: A need for tackling the conceptual crisis. Frontiers in Psychology, 8, 1-5. https://doi.org/10.3389/fpsyg.2017.00568

Metcalfe, J., \& Mischel, W. (1999). A hot/cool system analysis of delay of gratification: Dynamics of willpower. Psychological Review, 106, 3-19. https://doi.org/10.1037/0033-295x.106.1.3

Milkman, K. L., Minson, J. A., \& Volpp, K. G. (2013). Holding the hunger games hostage at the gym: An evaluation of temptation bundling. Management Science, 60, 283-299. https://doi.org/10.1287/mnsc.2013.1784

Milyavskaya, M., Berkman, E. T., \& De Ridder, D. T. D. (2019). The many faces of self-control: Tacit assumptions and recommendations to deal with them. Motivation Science, 5, 79-85. https://doi.org/10.1037/mot0000108

Milyavskaya, M., \& Inzlicht, M. (2017). What's so great about self-control? Examining the importance of effortful self-control and temptation in predicting real-life depletion and goal attainment. Social Psychological and Personality Science, 8, 603-611. https://doi.org/10.1177/1948550616679237

Mischel, W. (1974). Processes in delay of gratification. In Advances in experimental social psychology (Vol. 7, pp. 249-292). Amsterdam, Netherlands: Elsevier Academic Press.

Mischel, W., \& Baker, N. (1975). Cognitive appraisals and transformations in delay behavior. Journal of Personality and Social Psychology, 31, 254-261. https://doi.org/10.1037/h0076272

Mischel, W., Ebbesen, E. B., \& Raskoff Zeiss, A. (1972). Cognitive and attentional mechanisms in delay of gratification. Journal of Personality and Social Psychology, 21, 204-218. https://doi.org/10.1037/h0032198

Mischel, W., Shoda, Y., \& Rodriguez, M. L. (1989). Delay of gratification in children. Science, 244, 933-938. https://doi.org/ 10.1126/science.2658056

Moffitt, T. E., Arseneault, L., Belsky, D., Dickson, N., Hancox, R. J., Harrington, H., ... Caspi, A. (2011). A gradient of childhood self-control predicts health, wealth, and public safety. Proceedings of the National Academy of Sciences of the United States of America, 108, 2693-2698. https://doi.org/10.1073/pnas.1010076108

Moshontz, H., \& Hoyle, R. H. (2019, November 5). Resisting, recognizing, and returning: A three-component model and review of persistence in episodic goals. https://doi.org/10.31234/osf.io/b8pxq

Myrseth, K. O. R., \& Fishbach, A. (2009). Self-control: A function of knowing when and how to exercise restraint. Current Directions in Psychological Science, 18, 247-252. https://doi.org/10.1111/j.1467-8721.2009.01645.x

Nielsen, K. S., Gwozdz, W., \& De Ridder, D. (2019). Unraveling the relationship between trait self-control and subjective well-being: The mediating role of four self-control strategies. Frontiers in Psychology, 10, 1-10. https://doi.org/10.3389/ fpsyg.2019.00706

Oettingen, G., Pak, H. J., \& Schnetter, K. (2001). Self-regulation of goal-setting: Turning free fantasies about the future into binding goals. Journal of Personality and Social Psychology, 80, 736-753. https://doi.org/10.1037/0022-3514.80. 5.736

Peake, P. K., Hebl, M., \& Mischel, W. (2002). Strategic attention deployment for delay of gratification in working and waiting situations. Developmental Psychology, 38, 313-326. https://doi.org/10.1037/0012-1649.38.2.313

Pearlin, L. I., \& Schooler, C. (1978). The structure of coping. Journal of Health and Social Behavior, 19, 2-21. https://doi.org/ $10.2307 / 2136319$ 
Pintrich, P. R. (2000). The role of goal orientation in self-regulated learning. In M. Boekaerts, P. R. Pintrich, \& M. Zeidner (Eds.), Handbook of self-regulation (pp. 451-502). San Diego, CA: Academic Press. https://doi.org/10.1016/B978012109890-2/50043-3

Rodin, R., Bonanno, G. A., Knuckey, S., Satterthwaite, M. L., Hart, R., Joscelyne, A., ... Brown, A. D. (2017). Coping flexibility predicts post-traumatic stress disorder and depression in human rights advocates. International Journal of Mental Health, 46, 327-338. https://doi.org/10.1080/00207411.2017.1345047

Ryan, R. M., Sheldon, K. M., Kasser, T., \& Deci, E. L. (1996). All goals are not created equal: An organismic perspective on the nature of goals and their regulation. In P. M. Gollwitzer \& J. A. Bargh (Eds.), The psychology of action: Linking cognition and motivation to behavior (pp. 7-26). New York, NY: Guilford Press.

Sansone, C., Weir, C., Harpster, L., \& Morgan, C. (1992). Once a boring task always a boring task? Interest as a selfregulatory mechanism. Journal of Personality and Social Psychology, 63, 379-390.

Sarason, I. G., Sarason, B. R., \& Pierce, G. R. (1990). Social support: The search for theory. Journal of Social and Clinical Psychology, 9, 133-147. https://doi.org/10.1521/jscp.1990.9.1.133

Saunders, B., Milyavskaya, M., Etz, A., Randles, D., \& Inzlicht, M. (2018). Reported self-control is not meaningfully associated with inhibition-related executive function: A Bayesian analysis. Collabra: Psychology, 4, 39. https://doi.org/10.1525/ collabra.134

Schunk, D. H. (1990). Goal setting and self-efficacy during self-regulated learning. Educational Psychologist, 25, 71-86. https://doi.org/10.1207/s15326985ep2501_6

Sniehotta, F. F., Scholz, U., \& Schwarzer, R. (2005). Bridging the intention-behaviour gap: Planning, self-efficacy, and action control in the adoption and maintenance of physical exercise. Psychology and Health, 20, 143-160. https://doi.org/10. 1080/08870440512331317670

Tangney, J. P., Baumeister, R. F., \& Boone, A. L. (2004). High self-control predicts good adjustment, less pathology, better grades, and interpersonal success. Journal of Personality, 72, 271-324. https://doi.org/10.1111/j.0022-3506.2004. 00263.x

Van Gog, T., Kester, L., \& Paas, F. (2011). Effects of concurrent monitoring on cognitive load and performance as a function of task complexity. Applied Cognitive Psychology, 25, 584-587. https://doi.org/10.1002/acp.1726

Wiese, C. W., Tay, L., Duckworth, A. L., D'Mello, S., Kuykendall, L., Hofman, W., ... Vohs, K. D. (2017). Too much of a good thing? Exploring the inverted-u relationship between self-control and happiness. Journal of Personality, 86, 380-396. https://doi.org/10.1111/jopy.12322

Woolley, K., \& Fishbach, A. (2015). The experience matters more than you think: People value intrinsic incentives more inside than outside an activity. Journal of Personality and Social Psychology, 109, 968-982. https://doi.org/10.1037/ pspa0000035

Zimmerman, B. J. (1990). Self-regulated learning and academic achievement: An overview. Educational Psychologist, 25, 3-17. https://doi.org/10.1207/s15326985ep2501_2

Zimmerman, B. J. (2000). Attaining self-regulation: A social cognitive perspective. In M. Boekaerts, P. R. Pintrich, \& M. Zeidner (Eds.), Handbook of self-regulation (pp. 13-39). San Diego, CA: Academic Press. https://doi.org/10.1016/ B978-012109890-2/50031-7

Zimmerman, B. J., Bandura, A., \& Martinez-Pons, M. (1992). Self-motivation for academic attainment: The role of selfefficacy beliefs and personal goal setting. American Educational Research Journal, 29, 663-676. https://doi.org/10.2307/ 1163261

\section{AUTHOR BIOGRAPHIES}

Marie Hennecke is a professor for General and Educational Psychology in the Department of Psychology at the University of Siegen, Germany. Previously, she completed her undergraduate studies as a scholarship holder of the German academic foundation at the University of Bochum, Germany, and received her doctorate from the University of Zurich, Switzerland, where she was furthermore a graduate student in the International Max Planck Research School on the Life Course. After the doctorate, she completed a post-doctoral fellowship funded by the Swiss National Science Foundation at the University of Virginia before returning to the University of Zurich as an Assistant Professor and recently moving to the University of Siegen. Her research is devoted to understanding the behavioral dynamics and psychological processes involved in goal setting and goal pursuit. Zooming in on self-regulation, she tries to understand the processes that distinguish people who are successful at regulating their thoughts, actions, and emotions from people who are less successful in doing so. Zooming out, she 
furthermore tries to understand the pivotal role of self-regulation for people's health, well-being, and lifespan development. Her research methods range from laboratory experiments to experience sampling. You can find her on Twitter (@m_hennecke).

Sebastian Bürgler is a doctoral student in General and Educational Psychology at the University of Siegen, Germany. He completed his Msc and BSc in Psychology at the University of Zurich, Switzerland. During his studies at the University of Zurich, Sebastian has worked as a student research assistant in several fields of psychology, including Geriatric Psychology, Clinical Psychology, and Neurology. Sebastian's current research in selfregulation examines the role of flexibility, strategy repertoire, self-knowledge, as well as self-monitoring and selfreflection in the context of daily self-control conflicts. Sebastian is furthermore interested in technological advances in psychological research and practice, such as apps for ecological momentary assessments.

How to cite this article: Hennecke M, Bürgler S. Many roads lead to Rome: Self-regulatory strategies and their effects on self-control. Soc Personal Psychol Compass. 2020;14:e12530. https://doi.org/10.1111/spc3. 12530 